\title{
VITAMIN C AND ITS EFFECTS ON THE STRUCTURE OF THE TEETH
}

BY

\author{
A. T. PITTS, D.S.O., M.R.C.S., L.D.S.,
} Consulting Dental Surgeon, Hospital for Sick Children, Great Ormond Street; Dental Surgeon, Royal Dental Hospital and Middlesex Hospital.

Since scurvy, whether occurring in adults or infants has been recognized, the effect of this disease on the gums has been familiar. The sequence of events, swelling, bleeding from the gums and progressive loosening of the teeth, is well known. It is interesting to note that in infantile scurvy these changes only occur when teeth are present or just on the point of eruption. In their early experimental research into the action of vitamin C, Holst and Frölich ${ }^{9}$ in 1912 noted in guinea-pigs the occurrence of swelling of the gums and loosening of the teeth, but the first observation on the effect of vitamin $\mathbf{C}$ deficiency on actual tooth structure seems to have been that of Jackson and Moore ${ }^{11}$ in 1916, who noted the presence of haemorrhages in the pulps of the teeth in guinea-pigs. This was the first account of the effect of vitamin $\mathrm{C}$ deficiency on tooth structure as opposed to the supporting structures, such as alveolar bone, periodontal membrane and gum.

The next stage was the work of Zilva and Wells ${ }^{18}$ who showed that changes occur in the pulps of the teeth in guinea-pigs when deprived of vitamin C. Not only haemorrhages occur but a series of changes in the cellular structure are found which lead eventually to a disintegration of the cells and their replacement by fibrous tissue. Zilva and Wells described the changes as being in the nature of a fibrous degeneration. They found that the mildest degree of scurvy which could be recognized at post-mortem examination produced changes in the teeth of guinea-pigs. In more advanced degrees of scurvy the odontoblast layer of cells became disorganized until, eventually, all traces of cellular organization were lost and replaced by fibrous tissue. The fine fibrillar connective tissue which normally forms a supporting network in the dental pulp, either became grossly hypertrophied or else replaced by a new form of fibrous tissue devoid of cells. The dentine was irregular and osteoid. In view of the fact that the teeth are the first structures to be affected in experimental scurvy, Zilva and Wells made the interesting suggestion that transient conditions of infantile scurvy may occur more frequently than had been supposed and that it is not unreasonable to assume that the teeth may be affected in this way.

Following the work of Zilva and Wells came the investigations of P. R. Howe ${ }^{10}$, alone or in conjunction with other workers, from 1920 on- 
wards. In 1920 Howe noted that a scorbutic diet made the teeth of guinea-pigs become elongated, irregular and loose. $\mathrm{He}$ described the dental findings as simulating pyorrhoea more closely than any pathological condition of the teeth artificially produced. He found that lesions of the dental pulp occurred before grosser indications of scurvy became manifest. The actual diet given is not stated, and though it may be concluded that it was deficient in vitamin $\mathrm{C}$, yet it is not known how far other vitamins were present or inadequate.

In 1923 Howe carried the picture further. When guinea-pigs were fed on a diet adequate in all respects except vitamin $\mathrm{C}$, extensive decalcification of enamel and dentine occurred regularly with the formation of cavities. The teeth became loose and elongated, with pus formation. These effects could be cured by the addition of orange juice to the diet. $\mathrm{He}$ also found that tartar was deposited on the teeth when vitamin $\mathrm{C}$ was withheld and that this disappeared when orange juice was added to the food.

A closer study of the changes produced in the teeth of guinea-pigs by a diet deficient in vitamin $\mathbf{C}$ was made by $\mathbf{G}$. Toverud ${ }^{15}$. She found that the orthodentine (normal tubular dentine) was replaced by osteodentine, a coarse dentine without tubules and resembling bone, which normally closes the pulp chamber towards the cutting edge as the tooth is worn away, but in far less amount in scurvy. The osteodentine, including degenerating odontoblasts, reached toward the apex of the tooth and there was only a narrow zone of normal dentine surrounding it. The pulp tissue was so degenerated that scarcely any of the normal cellular elements could be recognized, and in severe cases the only trace found was the presence of degenerated odontoblasts. Fatty degeneration was frequently present. The process of cellular disintegration began by haemorrhages in the upper part of the pulp and extended towards the base of the tooth. The degree of degeneration varied according to the length of time the animal had been on a scorbutic diet. Some chemical analyses of scorbutic teeth were given by Toverud. The results show a reduction in the amount of ash and calcium and an increase in magnesium in scorbutic teeth as compared to normal. The reduction of ash and calcium was not so marked as the histological appearances would suggest and Toverud explained this on the grounds that the pulp chamber was partly filled up with pathological calcified tissue. The reduction in ash and calcium and the increase in magnesium was greatest in those animals fed on a diet deficient in calcium as well as vitamin $C$. Toverud regards the substitution of calcium by magnesium as nature's attempt to maintain the amount of salts in the tooth when calcium is not available, but it is a pathological process and should be regarded as a form of osteomalacia. Toverud points out that in the guinea-pig the teeth are constantly growing and it may be that an animal with teeth of limited growth, as in man and most animals, when fed on a scorbutic diet, may be unable to form normal tooth tissue. 
Perhaps the most important work on the effect of a scorbutic diet on the teeth is that of A. Höjer ${ }^{6}$ which appeared in 1924 and at once attracted much attention. In common with other investigators, Höjer used the guinea-pig. Not only were the teeth investigated but the whole effect of scurvy was considered. The experimental animals were given a basal diet complete in all respects except that it contained no anti-scorbutics. The basal diet consisted of crushed oats, bran, and milk freed from vitamin $\mathrm{C}$ by being strongly aerated at $100^{\circ} \mathrm{C}$. for one hour. Out of 63 animals fed exclusively on this diet, 58 showed signs of scurvy. Höjer's theory of the action of vitamin $\mathrm{C}$ is that its presence is necessary to enable highly-organized, quickly-growing, active cells to perform their proper tasks. When vitamin $\mathbf{C}$ is lacking the cells sink to a lower grade and yield a product which in quantity and quality differs from normal. This is well shown in the formative cells of the teeth which by degrees stop their activity and eventually die.

The changes in the teeth of guinea-pigs occur at an early stage of vitamin $\mathbf{C}$ deficiency and afford the surest clinical sign of scurvy in its Iatent stages. As early as eight days on a completely scorbutic diet the first changes from the normal can be seen in the teeth. The arrangement of the odontoblast cells (the cells which line the tooth pulp and are responsible for the formation of dentine) becomes altered. They lose their shape and their processes disappear. There is an amorphous calcification in the odontogenetic zone (predentine) which stains deeply. Finally, there is a complete disappearance of the odontoblasts. On the inner side of this amorphously calcified tissue a hard tissue is deposited which seems to arise from calcification of collagen fibrils. During its growth it appears to become organized into a bony but spongy and porous calcified connective tissue, called by Höjer, pulp bone. The extent of the changes depends on the course of the disease. In absolute scurvy the changes in the pulp are characterized by destruction of tissue and there is very little formation of pulp bone. The cdontoblasts disappear rapidly while dilatation of the blood vessels and haemorrhages are coincident with necrosis of portions of the pulp. In some sections hollows filled with fluid were seen. Höjer noted a peculiar form of destruction of the dentine already formed at the onset of scurvy; it becomes porous through widening of the tubules so that the walls break down and adjoining tubules become confluent.

\section{Changes in mitigated scurvy.}

Animals with an anti-scorbutic dose of 0.5 c.c. of special orange juicc developed latent scurvy. The sequence of changes in the teeth was slower and the tissue destruction less prominent. Isolated odontoblasts were seen which resisted changes. Many osteoblasts were present which formed pulp bone. This latter grew in strongly-branched bundles towards the centre of the pulp. Structurally, the pulp bone consisted of pulp tissue enclosed in large spaces, with small bone canals, vessels and osteoblasts. If an animal fed on a scorbutic diet was given an anti-scorbutic diet the 
tooth changes were different. They were characterized by the formation of pulp bone and a new formation of odontoblasts which again became normally arranged. The reorganization of the bone of the jaw progressed concurrently with the healing changes in the teeth. Like Zilva and Wells, Höjer found that the changes in the teeth were one of the earliest signs of experimental scurvy. But he disagreed with their view that the essential nature of the change in tooth structure was the formation of fibrous tissue and was a degeneration. He considered that the changes were the result of a metaplasia of the cells tending toward the formation of new pulp tissue together with bone and produced by actively growing cells of an osteoblast type. The normal pulp is replaced by tissue resembling mature connective tissue. The complete fibrosis with no trace of cellular activity, as described by Zilva and Wells, has never been seen by Höjer.

A summary of the various changes in tooth structure in varying degrees of scurvy as described by Höjer may be given as follows :

Bone changes. The bone of a jaw already calcified at the onset of scurvy becomes porous through spaces forming in the marrow spaces and bone canals. There is a formation of new bone, chiefly on the outer surface of the bone, but also as connecting tracts within the marrow spaces. This new bone is deficient in collagen and inferior in quality.

Tooth changes. 1. The gradual change in appearance and eventual disappearance of the odontoblasts is the first sure sign of scurvy.

2. Amorphous calcification of the predentine occurs with absence of tubules in this layer.

3. The dentine already calcified at the onset of scurvy becomes porous through a dilatation and confluence of the dentinal tubules.

4. There is a formation of spongy bone-like tissue in the pulp instead of dentine.

5. Dilatation of the vessels and haemorrhages in the pulp.

6. Necrosis of the pulp and hydroptic changes.

7. Resorption of the pulp bone and dentine; atrophy of the pulp tissue appearing after the new formation of the bone in the pulp has stopped.

8. In scurvy, latent or mild in character, the changes in the teeth are similar though not so pronounced.

9. With doses of from 0.5 to 0.7 of the minimum protective antiscorbutic dose, the irregular dentine laid down is tubular but in the lingual part of the tooth pulp there are symmetrically arranged ridges of pulp bone with canals. The hard tissues contain bone canals and in some places enclosed cells which later may be transformed into dentine.

10. With more than 0.8 of the anti-scorbutic dose there is no formation of pulp bone, but the newly-formed tissue in the pulp resembles osteodentine.

\section{Criticisms of Höjer's work.}

Höjer's work was the fullest account of experimental scurvy which had then appeared. It has not escaped criticism, although all succeeding workers have supported his main contention that the earliest changes 
indicative of scurvy in the guinea-pig appear in the teeth. S. B. Wohlbach and P. R. Howe ${ }^{17}$, in 1926, criticized Höjer's findings in several important respects and provided an ingenious explanation of the mechanism of the changes in the teeth. These workers believe that Höjer's findings were based on incomplete scurvy. They did not find any formation of pulp bone or osteodentine and considered that Höjer's diets were not completely deficient in the anti-scorbutic substance, for they found that appearances resembling those described by Höjer only occurred in guineapigs fed alternatively on a normal diet and a defective diet. They regard the histological appearance as representing the healing process induced by giving a dose of anti-scorbutic substance, instead of being due to scurvy as believed by Höjer. In complete scurvy Wohlbach and Howe described changes in the odontoblast layer occurring in from seven to twelve days and affecting the apical end of the tooth. The earliest change was a separation of the layer of odontoblasts from the dentine by a narrow margin. There were occasional deposits of calcium in the odontogenetic zone (predentine) and irregularities of the odontoblasts. The individual cells became smaller and stained more densely. The blood vessels in the pulp and the capillaries penetrating the odontoblast layer were more apparent. Occasional deposits of a basic staining material were seen, which Wohlbach and Howe interpreted as being due to calcium salts, while between the processes of the odontoblasts the evidence of continued dentine formation could be inferred from the presence of hyaline globules which they regarded as the matrix of calcospherites. After a longer period than twelve days there was a complete separation of the odontoblasts from the dentine with rupture of their processes, while the spaces between the odontoblasts and the dentine were unstained. These spaces resembled vacuoles and the authors concluded that they were caused by the accumulation of liquid material. The odontoblasts were smaller and stained more deeply. The pulp was oedematous and in places a deposit of finely granular material was seen between the connective tissue cells which might possibly represent an early deposit of calcium salts. Finally, in complete scurvy there was a picture of a shrunken pulp completely detached from the dentine and apparently floating in a liquid material. Contrary to the findings of Höjer, no bone was present and the new formation of intracellular matrix of bone and dentine had ceased. The administration of orange juice resulted in the prompt appearance of new dentine. In 24 hours, 2 c.c. only of orange juice given to a guinea-pig kept for twelve days on a scorbutic diet, resulted in the formation of a zone of dentine on the separated odontoblasts. A dose of 8 c.c. daily of orange juice for three days brought about a complete filling of the space between odontoblasts and dentine in scurvy of long standing. It was found that the newly-formed dentine might be thicker than the original dentine and that it followed the irregular contours of the odontoblast layer, which were due to the development of scurvy. This filling up of the space by dentine proceeded from the surface of the odontoblasts. Its rapidity and appearance before any discernible change in the cells indicated that the process 
was one of setting or gelling of a liquid material. Wohlbach and Howe concluded that the liquid separating the odontoblasts and the dentine was a defective secretion of the cells formed in excess of the normal rate. This explanation accounts for the larger volume of dentine as compared with the original tissue. The missing factor which the anti-scorbutic agent enables the odontoblasts to supply is evidently one affecting the gelling of the liquid. Wohlbach and Howe characterize the condition of scurvy as being an inability of the supporting tissues to produce and maintain the intercellular substance. They advance the theory that the failure of cells to produce an intercellular substance in scurvy is due to the absence of an agent common to all supporting tissues which is responsible for the setting or gelling of a liquid product. This reaction may possibly be reversible.

\section{Recent work.}

The latest important work on the changes in the teeth in experimental scurvy was reported by E. W. Fish and L. J. Harris ${ }^{3}$ in 1934. One important point made by these workers is that since the teeth of the guineapig are of persistent growth, sections at different levels may show the dental tissues in an embryonic stage, in a state of maturity or in a condition of senility and degeneration. When a tooth is examined to determine the local result of a special diet it is important to know which part was already formed when the special diet began to take effect and that which was formed after this date, since the structural effects of hypovitaminosis on the hard tissues are restricted to the part of the tooth formed after the diet has affected the metabolism of the animal. For this reason these workers used longitudinal sections of a fold of a cheek tooth and not transverse sections of the incisor teeth as used by Höjer and others. This obviates the fallacies which may result from using transverse sections of the incisor teeth which can show at one level odontoblasts in full activity and at a higher level cells in a state of degeneration. In fact the changes described as due to scurvy may be found occurring in various parts of the same tooth in a normal guinea-pig. Unless it is possible to ensure that a transverse section of an incisor tooth goes through a part of a tooth which has been formed subsequently to the ingestion of a diet deficient in vitamin $\mathbf{C}$ so that the results are a true index of the changes induced by that diet, then the findings may be open to suspicion. Another point of significance made by Fish and Harris is that secondary dentine is normally laid down at the senile, i.e., apical, end of the incisor teeth and that this tissue is identical with the 'osteodentine' described by Höjer as a result of ' subscurvy.' They describe the effects of scurvy in the guinea-pig as an acceleration of the process of degeneration which occurs normaliy at the apical end of the teeth where the pulp cells have finished their active function. But instead of the senile odontoblasts at the apex dying, the younger odontoblasts all the way down the pulp also share in this change and become sealed off by a barrier of calcific tissue. In 
' subscurvy' the connective tissue cells remain alive for a time, but degeneration sets in and their fibrils become detached and a deeply staining deposit of calcium salts is laid down over the ends of the dentinal tubules which seals them off from the pulp. Lime salts are formed throughour the pulp in a collagen matrix which encloses islets of the degenerating cells and resembles the normal calcific material at the senile end of a healthy tooth. In fully-developed scurvy the phenomena are modified because the pulp is more severely affected. All the odontoblasts die as well as the primary dentine. This latter is sealed off by a deeply stained barrier of lime salts. But the pulp is unable to continue to react and lays down a collagen matrix as in 'subscurvy.' Even at the developing end of the tooth where cellular activity is greatest, no primary dentine is formed but only a narrow band of amorphous lime salts.

In addition to the modifications in dentine and pulp, Fish and Harris find changes in the ameloblasts (enamel-forming cells). These are, however, affected later than the odontoblasts. In 'subscurvy' the enamel continues to form without appreciable change. But in fully-developed scurvy it completely fails to do so. The ameloblasts either disappear or become keratinized so that if the animal is cured by being given a fully protective dose of anti-scorbutic substance, there will never be any enamel on that part of the tooth which was forming when the scurvy was at is height. The cementum, by which a tooth is fixed into the jaw bone, is affected similarly to the dentine and its formative cells in the periodontal membrane degenerate like the odontoblasts.

The pulp-bone or osteodentine theory of Höjer is severely criticized by Fish and Harris, who argue with much force that this tissue is not bone and not an essential sign of 'subscurvy.' They regard it as secondary dentine which acts as a scar or barrier to dentine which has died and is part of the protective mechanism which occurs in every tooth undergoing irritation, whether physiological or pathological. A similar formation can be induced in a tooth by mechanical injury to a growing tooth. For these reasons Fish and Harris reject the view that the formation of 'pulp-bone' is a neoplastic growth specific to scurvy.

If these views, which correspond in essentials to the earlier work of Wells and Zilva and of Wohlbach and Howe, are to be accepted then the elaborate series of changes described by Höjer in scurvy, incomplete scurvy and healing scurvy, must require modification. But even if Höjer's work be open to doubt in many of its details, yet his very complete investigations still remain of value. It provided clear proof of the early effect of scurvy on the teeth and gave a great impetus to other work on the subject.

\section{Biological testing.}

An interesting development of Höjer's work is its application as a means of testing the anti-scorbutic potency of various foodstuffs by noting the changes produced on the teeth of experimental guinea-pigs. A series of 
papers by Höjer ${ }^{8}$ and other workers appearing from 1926 onwards testify to the scope of this method of biological assay of anti-scorbutic potency. Höjer's technique may be summarized as follows :

Young guinea-pigs from a certain day are fed on a basal diet free from anti-scorbutic factors but otherwise complete. To. this diet is added quantitative daily doses of the juices to be examined. Controls of animals on the basal diet alone and others on fully-protective dose of a known antiscorbutic are also used. After ten to fourteen days all the animals are killed. The jaws are decalcified and a cross-section of the incisors examined. Höjer has formulated a series of changes affecting the odontoblasts, predentine and dentine, corresponding to various degress of scurvy thus induced. A value of one is given to a fully protective dose and corresponds to the appearance in a normal tooth. Höjer claims that by this method it is possible to graduate accurately degrees of protection less than the full and ranging from 0.9 of the protective dose to complete scurvy, which is given the value of 0 . Clinically, Höjer has found this method useful. In February, 1925, he examined the anti-scorbutic value of milk sold as suitable to the Children's Hospital in Stockholm. A dose of 100 c.c. of this raw milk was given to each of four guinea-pigs. The histological picture showed that the amount was equivalent to 0.1 to 0.2 of the fully protective dose of a known anti-scorbutic. He concluded that 18 to 36 pints in the case of children represented a fully protective dose. In the summer when he tried to get rid of the anti-scorbutic substance in the milk by treating it with heated air for one hour there still remained so much vitamin $\mathrm{C}$ that the fully protective dose was only 4 to 7 pints per child. By this test Höjer concluded that winter milk may be deprived of its vitamin $\mathbf{C}$ but not summer milk. A similar experiment was made using Northern wild cloud berries which were shown to have as high an anti-scorbutic value as orange juice.

Höjer claims for this method of biological assay that it is accurate in fixing the full protective dose of any foodstuff and only requires three weeks as against three months by other methods. The appearance of this paper led to a considerable number of other works in which his method of assaying the anti-scorbutic potency of foodstuffs has been employed. M. Goettsch ${ }^{4}$, using Höjer's method, confirms its accuracy and finds that it is more reliable and delicate than the method of estimating the development and degree of scurvy by such changes as the length of survival period, presence of stiff joints, or microscopical signs at autopsy such as haemorrhages into the joints and enlargement of ribs. By Höjer's method the minimum protective dose of sweet orange juice is 3 c.c. and only 1.5 c.c. by the old method. Goettsch, however, found that there was a considerable variation in the appearances of the teeth. While it was possible to estimate the minimal protective dose with accuracy, such variations in the teeth occurred in any one group of experimental animals on any one inadequate diet that the value of an inadequate diet could not be determined without using a large number of animals.

G. Dalldorf and C. Zall ${ }^{1}$, instead of using differences in the structure of teeth to estimate anti-scorbutic values, studied the rate of growth of the persistently growing incisor teeth of guinea-pigs. "They claim that in scurvy the teeth grow more slowly than in normal animals. The rate of growth of the teeth was studied by clipping exposed nortions of one of 
the lower incisors for varying periods from 20 to 90 days. The normal rate of growth was established by using animals on a standard basal diet with the addition of cod-liver oil. In the group of animals free from scurvy the rate of growth was $0.850 \mathrm{~mm}$. daily in contrast to a minimal rate of $0.306 \mathrm{~mm}$. daily in controls. It was found that in every case the addition of vitamin $\mathrm{C}$ increased the rate of growth and that deficiency of the vitamin slowed the growth. In an earlier paper, Dalldorf ${ }^{2}$ described the lesions in skeletal muscles in experimental scurvy and showed that exercise and stress determined largely the location and degree of scorbutic lesions. Since an amputated tooth is subject to less stress than a tooth used for gnawing, Dalldorf and Zall studied the changes in the roots of the teeth. They found them similar to those described by Wohlbach and Howe. In complete vitamin deprivation the odontoblasts continued to regress and eventually changed into spindle and stellate forms resembling fibroblasts. If the diet contained only a small amount of vitamin C complete regression of the odontoblasts did not occur and instead of fibroblasts the cells came to resemble osteoblasts and formed an intercellular matrix similar to bone within the pulp. (This may explain the apparent discrepancy between the observations of Zilva, Höjer and Wohlbach and Howe.) Finally, in the late stages the pulp is filled with osteodentine. If the tooth has been clipped the evidence of scurvy both in the amount of osteodentine and the character of the cells, is less pronounced than in the unclipped tooth. This was true of all animals examined. In discussing these results Dalldorf and Zall state that the findings show that the scorbutic process is characterized by the inability of certain cells to form the intercellular substance natural to them. In partial deficiency an inferior substitute material may be formed less highly differentiated than dentine. When deprivation is complete the cells alter still further and form the still more primitive fibrous tissue. This process is similar to that occurring in long bones and costo-chondral junctions where osteoblasts appear unable to form bone matrix and become fibroblasts. With regard to the rate of growth of teeth Dalldorf and Zall conclude that there is a constant rate of growth of the incisor teeth in guinea-pigs in health. The deprivation of vitamin $\mathbf{C}$ causes the teeth to cease growing; the readministration of the vitamin restores growth to a degree roughly proportional to the dose of the vitamin. They suggest that under the standard conditions used for testing foodstuff for vitamin $\mathrm{C}$ the rate of tooth growth would appear to be a precise indication of the degree of scurvy, being more delicate than Sherman's method and more constant as well as more simple than Höjer's technique.

Using Höjer's method and its further elaboration by Goettsch, G. M. Key and G. K. Elphick ${ }^{12}$ have described a quantitative method of estimating vitamin $\mathbf{C}$ for which they claim great delicacy. If, as must be assumed, the normal structure of the teeth is entirely dependent on the presence of vitamin $\mathbf{C}$ in the diet, it follows that the degree of scurvy produced can be graded to doses of vitamin $\mathbf{C}$, provided that sufficient animals are given each dose in order to eliminate differences due to individual variations. 
If a relation could be found between the average amount of protection given by a dose of vitamin $\mathbf{C}$ and the dose itself, then the dose which would produce full protection could be calculated for an unknown substance. Key and Elphick determined the anti-scorbutic potency of graded doses of orange juice on the lines laid down by Höjer and Goettsch.

The experimental animals were divided into groups which received graduated doses of orange juice varying from 0 c.c., 0.75 c.c., 1.5 c.c. to 3.0 c.c. daily. The feeding was continued for fourteen days and the animals were killed. The appearances at autopsy showed that some difference could be found in the conditions of the joints, etc., between animals fed on a scorbutic diet and those receiving orange juice, but it was not possible to differentiate between the effect of varying doses of orange juice. Sections were made of the incisor teeth and the tissues examined. In order to determine the numerical value for the degrees of scurvy produced in each animal an arbitrary scale was devised in which values from 0 to 4 represented stages from severe scurvy to complete protection. These four stages depended on the appearance of the odontoblasts, the band of inner dentine, and the development of the predentine. Key and Elphick found that nearly all animals fitted into one of these groups though a few exceptions were found in which one part of the tooth indicated severe scurvy while other parts would justify inclusion in intermediate groups. Such sections were judged independently by two workers and an average degree of protection determined. It was found that the teeth of all animals having no orange juice showed severe scurvy. A dose of 3 c.c. of orange juice conferred complete protection in eleven out of fourteen animals. The effects of intermediate doses was more variable but it was assumed that the average value for fifteen guinea-pigs receiving each dose of juice represented the true protective power for that dose as determined by the arbitrary scale. The average dose plotted for the degree of protection from scurvy and plotted against the dose of orange juice gave a straight line. This curve could be used to compare any unknown substance with any standard. Key and Elphick claim that this method is more accurate than that used by Höjer and is particularly useful in determining the potency of substances containing little vitamin $\mathbf{C}$.

\section{Changes in other animals.}

It will be noted that all the investigations here described deal with the effect of deficiency of vitamin $\mathbf{C}$ on guinea-pigs. Apart from the susceptibility of this animal to scurvy which makes it so suitable for experimental work, it has teeth which grow from persistent pulps, a condition quite different from man and most mammals whose teeth are of limited growth and once formed can undergo but slight changes. For this reason it is difficult to draw conclusions which could be applied to the dental tissues of man. Experiments on dogs, whose teeth resemble those of man in being of limited growth, have failed to show that vitamin $\mathbf{C}$ has any effect on the teeth. Mrs. Mellanby ${ }^{13}$ for that reason concluded that it was improbable that the actual structure of human teeth was greatly affected by a deficient intake of vitamin C. It is, however, significant that L. J. Harris has shown that dogs, unlike humans, monkeys and guinea-pigs, do not require vitamin $C$. They can synthesize it in their bodies and therelors cannot suffer from vitamin $\mathbf{C}$ deficiency. The experiments on guinea- 
pigs as an index of what might happen in man, while of interest, fail in the important condition that the teeth are constantly being formed throughout life. This means that the pulp which is the formative tissue of the dentine is always of high functional activity, whereas in man once the dentine, is formed the pulp retains only a low degree of formative power. Thus any changes which may be induced by a deprivation of vitamin $\mathbf{C}$ are not likely to be shown in the teeth of man in the same way as in the teeth of persistent growth in guinea-pigs. This does not mean that a deficiency of vitamin $C$ may not be without effect on the health of the dental tissues of man but it increases the difficulty of estimating such changes if they exist. It is significant that the latest workers on the subject, Fish and Harris, propose to continue their investigations on monkeys whose teeth anatomically and physiologically closely resemble those of man.

The view has been expressed by Howe and others that a deficiency of vitamin $\mathbf{C}$ may be responsible for lesions of the supporting tissues and lead to pyorrhoea, partly on the evidence of loosening of the teeth in guinea-pigs suffering from scurvy and partly on the clinical investigations carried out by $\mathrm{Hanke}^{5}$ and a group of clinicians.

G. Westinn ${ }^{16}$ who has collaborated with Höjer in the latter's investigations, regards their findings in guinea-pigs as being valid for man. He finds evidence of the formation of masses of calcified tissue in the pulps in cases of human scurvy and considers that these are identical with the pulp-bone described by Höjer as a sign of scurvy in guinea-pigs. Metaplastic changes in the pulp with regression of odontoblasts and the formation of osteoblasts and fibroblasts may also be found. He would apparently go farther and regard these pulp changes as likely to indicate the presence of latent scurvy and to possess a diagnostic significance. But these masses of calcified tissue in the pulp of human teeth have long been known and are not uncommon. Similarly, changes in the pulp of a regressive nature are extremely common and occur as a reaction to caries. It is conceivable that in cases of human scurvy changes in the teeth comparable, so far as the different anatomical conditions permit, to those found in scorbutic guinea-pigs may also be present. But the reverse inference that these pulp changes, when present, are a sign of scurvy seems to be a proposition which has little to support it. M. Ohnell ${ }^{14}$ has also described cases of human scurvy with a formation of pulp stones and suggests that they possess diagnostic significance. He concludes that a generalized formation of pulp stones as demonstrated in x-ray pictures, should at once arouse a suspicion of scurvy. Here again, the chain of evidence seems too weak to carry such a generalization.

The work of Hanke ${ }^{5}$ represents the most ambitious attempt to found a dental pathology of scurvy in man on the effect of vitamin C deficiency. Hanke and his fellow workers claim to have cured cases of pyorrhoea by giving massive doses of orange juice. They found that children fed on a quart of milk, one-and-a-half ounces of butter, a pound of vegetables, half a pound of fruit and an egg a day, may develop dental caries and 
gingivitis. The addition of a pint of orange juice and that of one lemon to this diet supplied something which led to a disappearance of most of the gingivitis and an arrest of 50 per cent. of the caries. It would be easy to criticize this work and to point out that a diet containing such a large amount of vegetables and fruit-would scarcely be likely to be deficient in vitamin $\mathrm{C}$. The inference which might be drawn, namely, that the orange and lemon juice by virtue of its vitamin $\mathrm{C}$ supplied the necessary ingredient which reduced the liability to gingivitis and arrested the process of dental caries, might therefore be open to question. If the clinical results of giving orange and lemon juice as a supplementary ration to a diet which otherwise appears sufficient, are as stated by Hanke, then some other explanation must be sought. But while clinical investigations such as these must necessarily lack the precision of controlled laboratory experiments, they cannot be easily dismissed. It is probable that among many civilized communities vitamin $\mathrm{C}$ is likely to be deficient and the possibility must not be overlooked that minor deficiencies of this vitamin exist which fall short of actual scurvy but are sufficient to lead to impairment of the integrity of the dental tissues and thus predispose to dental disease.

\section{Summary.}

Scūrvy in guinea-pigs is easily produced by withholding vitamin C. Changes varying from slight alterations in the dentine and odontoblasts can be caused by deficiency of this vitamin. The result of complete scurvy leads to an entire disintegration of the cellular elements (Zilva and Wells). It is agreed by all workers that the earliest signs of scurvy are found in the teeth before any clinical signs are present. A sequence of changes in mitigated scurvy are described by Höjer which lead to the formation of bony tissue in the pulp. Wohlbach and Howe, and Fish and Harris both agree in denying the validity of these observations of Höjer. According to Fish and Harris this calcific tissue is the result of irritation comparable to the changes induced by mechanical irritation both in man and experimentally, and have not the significance of a metaplastic formation as postulated by Höjer. A further point of some importance made by Fish and Harris is that as the teeth of the guinea-pig are of persistent growth, cross-sections will show varying phases of functional activity at different levels in the same tooth and that some of the appearances assumed by Höjer to be due to vitamin C deficiency may well be normal for that particular stage of formation in the cross-section of the tooth examined. To get over this fallacy Fish and Harris have used longitudinal sections of the molar teeth so as to get a picture of the pulp at its different levels of senility at the tip, maturity in the middle of the tooth and active development at the open end of the root. By this method they claim to have obtained a true picture of the changes produced by vitamin $\mathbf{C}$ deficiency. They regard the effects of scurvy on the teeth as being an acceleration of the process of degeneration which occurs normally at the apical end of the teeth where the pulp cells have finished their active 
function but which extends all the way down the pulp so that the younger odontoblasts are affected and react by becoming sealed off by calcific tissue (the equivalent of the pulp-bone described by Höjer). They also find changes in the enamel-forming ceilis which in fully developed scurvy fail to form enamel. Wohlbach and Howe, as the result of their observations, find changes which finally result in a shrunken pulp completely detached from the dentine and floating about in a fluid. They regard this fluid as being a defective secretion of the cells formed in excess of the normal rate. The missing substance which the anti-scorbutic agent enables the odontoblasts to supply is one affecting the gelling of the liquid. Scurvy is in essence a condition in which there is an inability of the supporting tissues to maintain an intercellular substance. Chemical analyses of scorbutic teeth carried out by G. Toverud show that there is a reduction of ash and $\mathrm{CaO}$ and an increase of magnesium as compared with normal teeth. She regards the substitution of calcium by magnesium as being an attempt to maintain the amount of salt in the teeth when calcium is not available. A development of Höjer's work is the use which has been made by Höjer, Goettsch, Key and Elphick to estimate the anti-scorbutic efficiency of various substances by noting the effects on the teeth. Accuracy and speed of investigation are claimed for this method of biological assay. Dalldorf and Zall instead of relying on the histological changes in the pulp and dentine, have studied the rate of growth of the persistently growing incisors of the guinea-pig and find that in scurvy the rate of growth is diminished.

\section{Conclusions.}

In attempting to estimate the significance of this vast body of work on experimental scurvy one is faced with the difficulty that the experimental animal employed, the guinea-pig, differs in many important respects from man. The fact that the teeth are of persistent growth enables the effect of varying degrees of vitamin $\mathbf{C}$ deficiency on the dental tissues to be ascertained with ease since their formation proceeds pari passu with the action of the special diet on the organism. In man the teeth are of limited growth and thus any effect of scurvy on them, if it exists, cannot be demonstrated in the same way for tooth formation has already stopped. The dog, which as regards the teeth might behave like humans, is ruled out since it is not susceptible to scurvy. So far the monkey, which should provide the closest analogy to man, has not been used. How far is it possible to apply the results of the experiments on guinea-pigs to man with the implication that deficiency of vitamin $\mathrm{C}$ may be responsible for some aspects of dental disease? Hanke and his fellow workers have boldly drawn the conclusion that both gingivitis and dental caries may be affected by a lack of vitamin $\mathbf{C}$ and they claim that by giving massive doses of orange and lemon juice both these forms of dental disease can be greatly lessened. It would probably be agreed by dieticians that among many civilized communities there is often a 
shortage of vitamin $\mathrm{C}$ in the diet. In scurvy, whether affecting adults or children, the disease affects the supporting structures of the teeth and leads to gingivitis and progressive loosening: changes which are in many respects comparable to pyorrhoea. But florid scurvy of this type is now rare. The real interest in vitamin $\mathbf{C}$, as with other vitamins, is not so much the results of complete deprivation as the question as to whether relatively small deficiencies may predispose to various impairments of health. Is there any evidence that there is a tendency for children to suffer from a shortage of this vitamin and if so, may it be a factor predisposing or actual in the incidence of dental disease? To this question no decisive answer can be given. The work of Hanke is interesting and suggestive. Though lacking in complete proof yet taken in conjunction with the experimental work described, it suggests that vitamin $\mathbf{C}$ as well as vitamins $\mathbf{A}$ and $\mathbf{D}$ may be necessary to a normal development and function of the teeth and that any deficiency of this vitamin in the diet may be reflected in a lowered resistance of the teeth to disease. Since the average dietary may easily be deficient in vitamin $\mathbf{C}$ it is desirable to emphasize the importance of ensuring a plentiful supply of this vitamin during the all-important years of childhood when growth both of the teeth and other tissues is most active and when the susceptibility to dental disease is greatest.

\section{REFERENGES.}

1. Dalldorf, G., \& Zall, C., J. Exper. Med., New York, 1930, LII, 57.

2. Dalldorf, G., ibid., 1929, L, 293.

3. Fish, E. W., \& Harris, L. J., Phil. Trans. Roy. Soc. Lond., London, 1934 (Ser. B.), CCXXIII, 489.

4. Goettsch, M., Quart J. Pharm. and Pharmacol, Lond., 1928, I, 168.

5. Hanke, M. T., 'Diet and Dental Health,' Chicago, 1933.

6. Höjer, J. A., Acta Paediat., Uppsala, 1924, III, 8.

7. Höjer, J. A., \& Westinn, G., Dental Cosmos, Philadelph., 1925, LXVII, 1.

8. Höjer, J. A., Brit. J. Exper. Path., London, 1926, VII, 356.

9. Holst, A., \& Frölich, T., Ztschr. f. Hyg. u. Infectionskr., Berlin, 1912, LXXV, 344.

10. Howe, P. R., Dental Cosmos, Philadelph., 1920, LXII, 586; ibid., 1921, LXIII, 1086; J. Dent. Research, Baltimore, 1921, III, 9; J. Am. Dent. Assn., Chicago, 1923, X, 21.

11. Jackson, L., \& Moore, J. M., J. Infect. Dis., Chicago, 1916, XIX, 478.

12. Key, K. M., \& Elphick, G. K., Biochem. J., London, 1931, XXV, 888.

13. Mellanby, M., Med. Res. Counc. Spec. Rep. Ser., No. 140, Pt. 1, 1930.

14. Ohnell, M., Acta Med. Scandinav., Stockholm, 1928, LXVII, 176.

15. Toverud, G., J. Biol. Chem., Baltimore, 1923, LVIII, 583.

16. Westinn, G., Dental Cosmos, Philadelph., 1925, LXVII, 868.

17. Wohlbach, S. B., \& Howe, P. R., Arch. Path. \& Lab. Med., Chicago, 1926, I, 1.

18. Zilva, S. S., \& Wells, F. M., Proc. Roy. Soc. Ser. B., London, 1919, XC, 505. 